\title{
Individual condition and inflammatory response to PHA in the subterranean rodent Ctenomys talarum (Talas tuco-tuco): A multivariate approach
}

\author{
Julieta Leticia Merlo*,1, Ana Paula Cutrera, Marcelo Javier Kittlein, Roxana Rita Zenuto \\ Laboratorio de Ecología Fisiológica y del Comportamiento, Instituto de Investigaciones Marinas y Costeras, CONICET-Universidad Nacional de Mar del Plata, \\ Mar del Plata, Buenos Aires, Argentina
}

\section{A R T I C L E I N F O}

\section{Article history:}

Received 21 September 2017

Accepted 21 February 2018

Handled by Emmanuel Serrano

\section{Keywords:}

Immunity

Parasite load

Trichuris pampeana

Eosinophils

Monocytes

\begin{abstract}
A B S T R A C T
Several components of individual condition can modulate immune function in vertebrates. One of the most common techniques used by ecologists to estimate immune responsiveness in wild populations is the phytohemagglutinin (PHA)-skin test, which is usually considered a proxy of cell- mediated activity. To determine the influence of individual condition on the magnitude of this immune index we assessed the variability in the inflammatory response to PHA in the subterranean solitary rodent, Ctenomys talarum (Talas tuco-tucos), including 18 variables associated with different aspects of individual condition that are indicative of physical, physiological, parasitological and immunological state. A partial least square (PLS) regression analysis was performed on the condition and the response variables to identify those having greater contribution to overall variation in the response. The first two components explained together $77.5 \%$ of the maximum achievable explained variance in the inflammatory response to PHA (60\% of total variance). Abundance of eggs of Trichuris pampeana, eosinophil, monocyte and neutrophil counts, together with reproductive condition were identified as the most important variables affecting the inflammatory response. The first component negatively associated the inflammatory response to PHA with the abundance of the nematode T. pampeana, and with counts of eosinophils and monocytes. The second component negatively associated the inflammatory response to PHA with reproductive condition, neutrophils and eosinophils. We discuss the general negative effect of infection on the immune responsiveness of wild animals and highlight the usefulness of the multivariate approaches in providing information on physiology, parasitology and health relationships to assess patterns of variation in immune responses.
\end{abstract}

() 2018 Published by Elsevier GmbH on behalf of Deutsche Gesellschaft für Säugetierkunde.

\section{Introduction}

Immune function is a critical component of survival for vertebrates (Barnard and Behnke, 2006). However, within species, individuals show notable variation in the magnitude and effectiveness of their immune responses (Schmid-Hempel, 2003). It is

Abbreviations: FEC, fecal egg count; N:L, neutrophil-lymphocyte ratio; NAb, natural antibody; PBS, phosphate buffered solution; PHA, phytohemagglutinin; PLS, partial least squares regression; RBC, red blood cells; SRBC, sheep red blood cells; Th1, type $1 \mathrm{~T}$ lymphocyte; Th 2, type 2 T lymphocyte.

* Corresponding author at: División Electroquímica Aplicada, Instituto de Investigaciones en Ciencia y Tecnología de Materiales, CONICET-Universidad Nacional de Mar del Plata, J.B. Justo 4302, Mar del Plata, 7600, Buenos Aires, Argentina.

E-mail address: jmerlo@mdp.edu.ar (J.L. Merlo).

1 Present address: División Electroquímica Aplicada, Instituto de Investigaciones en Ciencia y Tecnología de Materiales, CONICET-Universidad Nacional de Mar del Plata, Buenos Aires, Argentina. known that the individual "condition" -the suborganismal environment in which the immune response manifests itself, defined by competing physiological demands on the host at the time of infection- influences immune performance (Lazzaro and Little, 2009). Several studies have evidenced the effect of different components of individual condition on immune function, but the majority of them have evaluated the influence of only a single or few indices of individual condition over immunity (e.g. genetic factors, Wakelin, 2009; heat and social stress, parental effort, Christe et al., 2011, Powell et al., 2013). Measures of individual condition are not independent indicators of some aspect of organismal functioning, but regulatory components of a single unified physiological system (Cohen et al., 2012). An effort to understand intra- and inter- specific variation in immune responsiveness, by measuring and analyzing a combination of proxies of individual condition, instead of using single parameters or simply body mass-based measures (Jakob et al., 1996; Peig and Green, 2009) is needed to understand the evolution of condition-dependent 
immune strategies and to delve deeper into questions of comparative immunology in general (Matson et al., 2006; Pedersen and Babayan, 2011; e.g.: Oliver-Guimerá et al., 2017). Besides, ecological studies of immune variation in wild populations have mostly involved birds, while other groups of vertebrates, such as mammals, remain much less investigated. Particularly, species with unique habits and uncommon life history traits are the focus of major interest for ecoimmunological studies, since they will provide information regarding diverse immune strategies.

The aim of this study was to assess the impact of individual condition on the inflammatory response of Ctenomys talarum (Talas tuco-tucos). Individual condition was assessed in an integral fashion, through the estimation of the physical (body weight, hematocrit), physiological (reproductive condition, stress, sex) and immunological/infection (parasite counts, leukocyte counts, agglutination capacity of plasma) state. The inflammatory response was assessed through the phytohemagglutinin (PHA)- skin test. This test has already been characterized in Talas tuco-tucos, which exhibit a large inter-individual variation in the magnitude of the swelling response (Merlo et al., 2014a). Thus, a more comprehensive analysis of the factors potentially associated with this response would contribute to determine the causes of its inter-individual variation. The use of PHA, although controversial regarding the type of immune components stimulated (Kennedy and Nager, 2006), allows the macroscopic quantification of inflammation in a simple manner, excluding additional processes (e.g. tissue damage, complex immune responses) associated with a real pathogenic infection. The Talas tuco-tucos are considered a "slow-living" species; they exhibit low basal metabolic rate (BMR), have long lifespans and long gestation periods ( 3 months) and give birth to altricial pups, only twice a year (Busch et al., 1989; Zenuto et al., 2002a,b). This contrasts with the majority of rodent species, which exhibit "fast-living" traits. Additionally, Talas tuco-tucos have subterranean habits, living in permanently sealed burrows and restricting most of their activities to these tunnels (Busch et al., 2000). Therefore, C. talarum is an interesting species for the study of immune strategies, since their life history traits and habits are uncommon among rodents and mammals in general. Moreover, much is known about the natural history, ecology, and physiology of this species (e.g. Busch et al., 2000; Luna and Antinuchi, 2007; Zenuto et al., 2002a,b), which can contribute to understand the context in which immune function varies. There is a clear synergism between infection and poor condition (Beldomenico et al., 2008a,b), in which parasites have detrimental effects on their host condition through reduction of hostís energy reserves and nutrients (Brown and Brown, 1989; Richner et al., 1993), and, in turn, poor condition predisposes to host infections, given that immunocompetence is impaired. For $C$. talarum, it is known that the energetic cost of the PHA response is low (Merlo et al., 2014a), but nevertheless, a reduction of $\sim 10 \%$ of body weight (induced by a low-calorie diet in captivity) reduces the inflammatory response to PHA in a 54\% (Merlo et al., 2016a). Also, it has been proposed that parasites trigger the activation of energy-consuming immune mechanisms (Beldomenico et al., 2008a,b; Sheldon and Verhulst, 1996), and can modulate, up-regulating or suppressing, the host resistance to other pathogens (Boughton et al., 2011; Cox, 2001). Based on this, we hypothesized that the inflammatory response of Talas tuco-tucos will be positively associated with a good physical and immunological condition (higher values of body weight, higher hematocrit and innate immunity levels -agglutination capacity of plasma-). In respect with infection, it is known that Talas tuco-tucos have a little diverse parasite fauna, but the prevalence of infection is high, probably as a consequence of burrow conditions that favour transmission (Rossin and Malizia, 2002). A previous study showed that in Talas tuco-tucos, PHA-triggered inflammation is similarly impaired by infection with an intestinal protozoan (Eimeria sp.) alone or co-occurring with a number of gastrointestinal nematode species (Merlo et al., 2016b). Thus, in general, we expect a negative association between the inflammatory response and infection (parasite load, leukocyte counts). However, given that immune responses against hematophagous ectoparasites are mainly cellmediated (Jones et al., 1996; Khokhlova et al., 2004) and that PHA also stimulates this immune branch of the immune system, we expected higher magnitudes of inflammation in response to PHA in individuals with greater loads of fleas, hematophagous mites or lice, as consequence of a potential synergism between immune challenges.

Physiological state of individuals - in this work assessed through the reproductive and stress condition- can also influence the magnitude of immune responsiveness. According to life-history theory, trade-offs between costly activities can maximize fitness and thus, immune suppression appears as a cost of current reproduction (Sheldon and Verhulst, 1996; van der Most et al., 2011), especially during energetically-demanding periods (Ardia, 2005; Deerenberg et al., 1997; Knowles et al., 2009). For this reason, reproductive state of individuals is an important factor to include in our analysis. Even though resource allocation to physiological systems are expected to change seasonally, it was reported not to significantly influence the magnitude of the response to PHA in a previous study in this species (Merlo et al., 2014b), while other studies have reported trade-offs between the inflammatory response to PHA and reproduction (Huyghe et al., 2010; Martin et al., 2004; Møller et al., 2003). Stress is also presumed to affect immunity, and this impact varies according to the duration and intensity of the stressor and the sensitivity of the immune component (Martin, 2009; Sapolsky et al., 2000). Stress is an adaptive response to diverse environmental, social and internal - physiological- stressors (Boonstra et al., 2001), in which energy is mobilized to safeguard immediate survival while other activities and processes like reproduction, growth and immune system are suppressed (see McEwen and Wingfield, 2010 for a review).

Finally, sex differences in immune responses are also well documented in vertebrates (Fargallo et al., 2002; Nunn et al., 2009; Restif and Amos, 2010), where males generally exhibit reduced immune responses as well as increased intensity and prevalence of infections compared to female conspecifics. Although differences in the response to PHA among sexes have not been previously reported for this species (Merlo et al., 2014b), this factor may contribute to the variance in the magnitude of inflammation.

\section{Material and methods}

\section{Animal capture and captivity conditions}

Adult Ctenomys talarum (Talas tuco-tucos) were live-trapped in the locality of Mar de Cobo, Buenos Aires Province, Argentina $\left(37^{\circ} 46^{\prime} \mathrm{S} 57^{\circ} 27^{\prime} \mathrm{W}\right.$ ) using wire tube-shaped live traps ( $10 \mathrm{~cm}$ diameter, $35 \mathrm{~cm}$ length) set at fresh surface mounds. Nursing females trapped, identified based on their enlarged nipples and missing hair around them, were immediately released back into their burrow system so as not to deprive dependent young of maternal care. Juveniles, which were identified based on their body weight (Malizia and Busch, 1991), were also released. A total of 48 animals were caught. Specifically, 10 males $(162 \pm 8.61 \mathrm{~g})$ and 10 females $(109.16 \pm 4.32 \mathrm{~g})$ were caught during the non-reproductive season (April to early May 2012), and 13 males (162.10 $\pm 4.18 \mathrm{~g})$ and 15 females ( $122.26 \pm 3.43 \mathrm{~g}$ ) were caught during the reproductive season (August to November 2012). Immediately after capture, feces of each animal were collected from traps (or from the tube in which each individual was transported, up to $5 \mathrm{~h}$ after capture) and conserved in $4 \%$ formalin. Additionally, a blood smear was 
made from a small sample of peripheral blood obtained from the tip of the tail, for leukocyte profile assessment (see below). Animals were transported to the Laboratory of Ecophysiology at the National University of Mar del Plata (Mar del Plata, Argentina). Their sex and weight at this time point was recorded, for later analysis, as well as the date (reproductive or non- reproductive season) in which they were caught. They were placed in individual plastic boxes $(25 \mathrm{~cm} \times 32 \mathrm{~cm} \times 42 \mathrm{~cm})$ provided with a wire-mesh lid and lined with wood shavings as bedding. Animals were fed ad libitum quantities of a mixture of chicory, lettuce, corn, sweet potatoes and sunflower seeds. Fresh food was provided daily to ensure water provision since $C$. talarum do not drink free water. Room conditions (temperature and photoperiod) were automatically controlled $\left(25 \pm 1^{\circ} \mathrm{C}, 12 \mathrm{~L}\right.$ : $\left.12 \mathrm{D}\right)$.

\section{Quantification of parasites}

In C. talarum, endoparasitic fauna is composed of gastrointestinal nematodes (Taenia talicei, Trichuris pampeana, Paraspidodera uncinata, Strongyloides myopotami, Trichostrongylus duretteae and Pudica ctenomyidis; Rossin and Malizia, 2002; Rossin et al., 2010, 2006), an hematophagous worm, Graphidioides subterraneus (Rossin et al., 2005) and an intestinal protozoan of the genus Eimeria, which presents a high prevalence in this species (Cutrera et al., 2011). The ectoparasites most frequently found in C. talarum are two species of lice (Eulinognathus americanus and Gyropus parvus; Martino et al., 2014), fleas (Poligenis sp.) and mites (Families Laelapidae and Listrophoridae; Cutrera et al., 2011).

Immediately upon arrival to the lab, animals were combed in a standardized pattern to obtain the ectoparasites trapped in the individual's pelage. Each animal was held over a white piece of paper while combed, and ectoparasites that fell onto the paper were then identified morphologically as fleas, lice or mites and counted using binocular lens (Olympus SZX7, Tokyo, Japan), as described by Cutrera et al. (2011). Mites were classified as "hematophagous" (Family Laelapidae, see Cutrera et al., 2011) or "non-hematophagous", which feed on skin debris (Family Listrophoridae, see Cutrera et al., 2011). This classification is useful for the purpose of this study since harm induced to the host depends on the feeding behavior of the parasite (hematophagous mites are expected to induce an important inflammatory response, whereas non-hematophagous mites can cause a lower harm to the skin).

To determine endoparasite loads, the number of parasite eggs/oocysts present in fecal samples collected immediately after capture was quantified. This procedure ensures the detection of all endoparasite present in Talas tuco-tucos, with the only exception of the species of Taenia talicei, which is found in the peritoneum and does not shed eggs in the feces (Cutrera et al., 2011; Rossin et al., 2004). Eggs/oocysts present in feces were assessed using the flotation technique proposed by Sheather (1923), as previously reported for C. talarum (Cutrera et al., 2011; Merlo et al., 2016b). Briefly, $1 \mathrm{~g}$ of wet feces of each animal was mixed with $15 \mathrm{ml}$ of Sheather's flotation solution (Sheather, 1923); then, $1 \mathrm{ml}$ of this fecal suspension was placed in each side of a McMaster chamber. After $10 \mathrm{~min}$, both sides of the chamber were observed for morphological identification of parasite eggs/oocysts, at $400 \mathrm{x}$ magnification (Olympus CX 31, Tokyo, Japan). For each egg/oocyst morphotype, fecal egg counts (FECs) were estimated per gram of wet feces (eggs/g). P. ctenomydis, G. subterraneus, S. myopotami, and T. duretteae eggs could not be differentiated and were all recorded a "strongylids," given their phylogenetic proximity and their relatively low abundance and prevalence, which is consistent with what was reported for the adult forms found in this population of $C$. talarum (Rossin et al.,
2010). Prevalence of each egg/oocysts type was estimated as the percentage of hosts shedding eggs/oocysts over all hosts examined.

\section{Blood collection and PHA- challenge}

Animals remained in captivity for 7 days before beginning the experiments because this is the necessary time lapse to acclimatize to captivity conditions and, hence, lower their stress levels (Vera et al., 2008). Therefore, $\sim 200 \mu$ l of blood were collected for analysis from the retro-orbital sinus of each individual 7 days after capture (see "Hematological parameters"). After this, the PHA- skin test was performed as described by Merlo et al. (2014a). Briefly, the thickness of the right hind foot of all animals was measured with a digital micrometer (Insize ${ }^{\circledR}$, Sao Paulo, Brazil) to the nearest $0.01 \mathrm{~mm}$, and the area was treated with an antiseptic solution (Pervinox, Phoenix laboratories, Buenos Aires, Argentina). Individuals were then injected subcutaneously in the instep of the right hind foot with PHA (Phaseolus vulgaris Sigma L-8754) solution dissolved in sterile phosphate-buffered saline ( $3 \mathrm{mg} / \mathrm{ml} ; 0.3 \mu \mathrm{l} /$ gram of weight) using a $30 \mathrm{G}$ needle. Thickness of the right hind foot of animals was measured again $24 \mathrm{~h}$ post-injection. The inflammatory response was calculated as the difference between pre- and postinjection thickness divided by initial thickness $(($ response $=$ (post pre)/pre); Xu and Wang, 2010; Merlo et al., 2014b). The repeatability of swelling measurements for the PHA- skin test was calculated from correlations (Brown et al., 2011) of two thickness measurements obtained from 27 animals caught in 2012 (unpublished results), including feet injected with PHA or PBS and different times post-injection $(6,12,24,48$ and $72 \mathrm{~h})$. Repeatability of thickness measurements for PHA/PBS injected feet was $0.81(\mathrm{P}<0.0001$, $\mathrm{n}=27$ )

\section{Hematological parameters}

\section{Hemolysis-hemagglutination assay}

The hemolysis-hemagglutination assay proposed by Matson et al. (2005) allows quantifying the natural antibody (NAb)mediated complement activation and red blood cell (RBC) agglutination (innate immune capacity measures) of each individual. These levels were assessed following Matson et al. (2005) and Merlo et al. (2016b; for this species). Levels of NAb-mediated complement activation and $\mathrm{RBC}$ agglutination were expressed as the negative $\log _{2}$ of the minimum plasma concentration that produce visible lysis/agglutination of the sample. For greater consistency, scoring of plates was always performed by the same person (JLM).

\section{Leukocyte profiles}

Leukocytes play specific roles during infection: the most abundant type in blood is lymphocytes, effectors of acquired responses, with long lifespan (Arjona Saz, 2006), and neutrophils, which play lytic and phagocytic roles during innate responses against bacteria, toxins and tissue trauma, with their levels lowering rapidly after antigenic stimuli disappears (Cuello-Gijón, 2006; Voigt, 2000). Other granulated and short lifespan leukocytes are eosinophils and basophils, both involved in allergies and response to parasites, especially extracellular parasites (e.g. helminthes; Salinas Lorente, 2006) in the case of eosinophils. Lastly, monocytes are associated with chronic infection or inflammation (Serbina et al., 2008). Additionally, during the stress response, released glucocorticoids alter the redistribution of lymphocytes from the blood to other body compartments (Dhabhar, 2009), also stimulating an influx of neutrophils into the blood from the bone marrow and down-regulating their exit from blood to other compartments (Bishop et al., 1968). Thus, these changes result in an increased neutrophil-lymphocyte ratio $(\mathrm{N}: \mathrm{L})$ in circulating blood, which can be used as an index of stress hormone levels (Davis et al., 2008; Müller et al., 2011). N: L is 
also increased in cases of severe systemic inflammation (Zahorec, 2001). In C. talarum, increases in $\mathrm{N}$ : L have been verified during captivity (Vera et al., 2008). Thus, although interpretation requires caution (Beldomenico et al., 2008a,b), relative counts of leukocyte types provide information about different infectious processes and stress (in this case, associated to captivity) that could be occurring in the individual (Voigt, 2000). Lymphocyte, neutrophil, eosinophil, monocyte and basophil abundances were quantified based on their morphology following standard protocols (Voigt, 2000), as previously done for this species (Cutrera et al., 2010, 2011; Merlo et al., 2014a; Vera et al., 2008), from blood smears obtained at the time of capture. Briefly, the number of each leukocyte type encountered until a total of 200 leukocytes had been examined. The proportion of each cell type present per 200 leukocytes was determined and the $\mathrm{N}$ : $\mathrm{L}$ ratio was calculated for each individual. Total leukocyte counts were recorded as the number of leukocytes encountered in 30 fields in which there was a single layer of erythrocytes $\sim 20,000$ erythrocytes, R. R. Zenuto, unpublished) and then standardized to 100,000 erythrocytes for comparative purposes (Bachman, 2003).

\section{Hematocrit}

Hematocrit is the proportion of blood volume occupied by packed red blood cells and is considered an indicator of general health status (Hoi-Leitner et al., 2001). Blood collected in a heparinized capillary tube $(\sim 60 \mu \mathrm{l})$ and centrifuged at $14,000 \mathrm{rpm}$ for $15 \mathrm{~min}$ (Cavour VT 1224 centrifuge, Buenos Aires, Argentina). Hematocrit was assessed as the proportion of capillary tube length occupied by packed red blood cells relative to the capillary tube length occupied by all blood components (Abaco CAV 1224, Buenos Aires, Argentina), as described in Cutrera et al. (2010).

\section{Statistics}

In addition to the magnitude of the PHA-induced response, a total of 18 condition variables were recorded as covariates from C. talarum individuals. These were estimates of physical (hematocrit, body mass), physiological (reproductive condition -according to the season of capture: "reproductive" or "nonreproductive" condition-, N: L as an estimate of stress and sex), and parasitological/immunological individual condition (counts of: fleas, hematophagous mites, non- hematophagous mites, Eimeria sp., P. uncinata, T. pampeana, lymphocytes, neutrophils, eosinophils, monocytes, basophils, total leukocytes, agglutination capacity of plasma). Titres of plasma lysis from hemolysis-hemagglutination assays were not included in the analysis given the low scores obtained ( 0 in the majority of the individuals), as well as lice counts (only 1 louse was found in 1 individual). All covariates were logtransformed prior to analyses.

We used the partial least squares (PLS) regression method to assess the relationships between condition variables and the PHAinduced response. PLS regression is appropriate when sample size is low relative to the number of variables and when collinearity occurs among covariates (Carrascal et al., 2009; Oliver-Guimerá et al., 2017). PLS regression finds principal components from a set of covariates $(\mathrm{X})$ that best predict the response variable $(\mathrm{Y})$. In particular, PLS regression searches for a set of components (called latent vectors, $\mathrm{LV}$ ) that perform a simultaneous decomposition of $\mathrm{X}$ and $Y$ with the constraint that these components explain as much as possible of the covariance between $\mathrm{X}$ and $\mathrm{Y}$ (Abdi, 2010).

The number of LVs in the analysis was established using the Stone-Geisser statistic $\left(\mathrm{Q}^{2}\right)$ at a threshold of 0.0975 . The $\mathrm{Q}^{2}$ statistic can be viewed as a leave-one-out cross validated $R^{2}$ (Abdi, 2010). A LV is kept in the analysis if its $Q^{2}$ statistic is larger than the threshold. As both continuous and categorical variables were used as covariates, we used the data processing method described by Russolillo and Lauro (2009). We obtained the "loading weights" (the relative contribution of each variable to the derived factors) and obtained their 95\% confidence intervals by non-parametric bootstrap to identify those covariates having a significant contribution to the LVs. All analyses were performed with the "plsRglm" (Bertrand et al., 2014) and "plspm" (Sanchez et al., 2017) packages in $\mathrm{R}$, version 3.4.1 ( $\mathrm{R}$ Core Team, 2016).

\section{Ethical note}

Talas tuco-tucos remained captive for the duration of the experimental assays ( $c a .10$ days) after which they were released at the point of capture. We adhered to the 2012 Revised International Guiding Principles for Biomedical Research Involving Animals developed by the Council for International Organizations of Medical Sciences (CIOMS) and the International Council for Laboratory Animal Science (ICLAS). Live-captures were performed according to the permit of capture number $22500-21222 / 13$ issued by the Ministry of Agricultural Affairs of the Buenos Aires Province.

Table 1

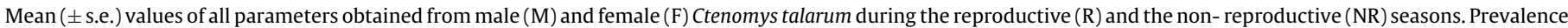
of parasites is shown between parentheses below their respective names.

\begin{tabular}{|c|c|c|c|c|}
\hline \multirow[t]{2}{*}{ Parameter } & \multicolumn{2}{|l|}{ NR } & \multicolumn{2}{|l|}{$\mathrm{R}$} \\
\hline & $M(n=10)$ & $F(n=10)$ & $M(n=13)$ & $F(n=15)$ \\
\hline PHA- response ${ }^{a}$ & $0.59 \pm(0.08)$ & $0.45 \pm(0.09)$ & $0.42 \pm(0.05)$ & $0.43 \pm(0.06)$ \\
\hline Body weight (g) & $162.0 \pm(8.61)$ & $109.16 \pm(4.32)$ & $162.10 \pm(1.16)$ & $122.26 \pm(0.89)$ \\
\hline Hematocrit (\%) & $47.5 \pm(1.14)$ & $44.0 \pm(1.14)$ & $43.70 \pm(1.56)$ & $44.73 \pm(0.70)$ \\
\hline Lymphocytes & $108.90 \pm(10.67)$ & $134.4 \pm(8.36)$ & $91.54 \pm(5.34)$ & $94.47 \pm(6.70)$ \\
\hline Neutrophils ${ }^{\mathrm{b}}$ & $77.40 \pm(10.09)$ & $56.40 \pm(7.87)$ & $90.15 \pm(4.44)$ & $89.47 \pm(6.52)$ \\
\hline Eosinophils $^{\mathrm{b}}$ & $9.0 \pm(2.35)$ & $5.20 \pm(1.51)$ & $12.62 \pm(2.01)$ & $10.67 \pm(1.95)$ \\
\hline Monocytes $^{\mathrm{b}}$ & $0.8 \pm(0.33)$ & $0.70 \pm(0.30)$ & $0.69 \pm(0.26)$ & $0.13 \pm(0.09)$ \\
\hline Basophils $^{\mathrm{b}}$ & $3.90 \pm(1.33)$ & $3.30 \pm(0.98)$ & $5.23 \pm(1.38)$ & $5.33 \pm(2.86)$ \\
\hline Total leukocytes/100,000 RBC & $7.95 \pm(3.08)$ & $10.89 \pm(2.04)$ & $6.92 \pm(1.25)$ & $10.37 \pm(1.32)$ \\
\hline Hemagglutination titres & $3.40 \pm(0.18)$ & $3.57 \pm(0.07)$ & $3.29 \pm(0.13)$ & $3.25 \pm(0.10)$ \\
\hline $\mathrm{N}: \mathrm{L}$ & $0.88 \pm(0.21)$ & $0.47 \pm(0.09)$ & $1.06 \pm(0.11)$ & $1.08 \pm(0.15)$ \\
\hline Fleas $(63.8 \%)$ & $0.80 \pm(0.36)$ & $3.10 \pm(2.77)$ & $4.92 \pm(1.30)$ & $2.93 \pm(0.80)$ \\
\hline Hematophagous mites (76.6\%) & $12.60 \pm(8.70)$ & $10.60 \pm(2.61)$ & $10.85 \pm(2.56)$ & $10.67 \pm(5.30)$ \\
\hline Non-hematophagous mites (76.6\%) & $8.20 \pm(3.40)$ & $9.40 \pm(2.60)$ & $3.92 \pm(1.17)$ & $8.40 \pm(4.00)$ \\
\hline Eimeria sp..$^{c}(97.9 \%)$ & $6,930 \pm(2,403)$ & $12,935 \pm(5,126)$ & $9,393 \pm(5,009)$ & $6,497 \pm(3,092)$ \\
\hline P. uncinata $(93.6 \%)$ & $620 \pm(167)$ & $800 \pm(193.5)$ & $1,950 \pm(446)$ & $1,657 \pm(399)$ \\
\hline T. pampeana ${ }^{\mathrm{C}}(31.9 \%)$ & $245 \pm(204.5)$ & $1,040 \pm(438)$ & $143 \pm(74)$ & $204 \pm(105)$ \\
\hline
\end{tabular}

a Calculated as the difference between pre- and post-injection thickness divided by initial thickness.

b Abundances based in a total of 200 leukocytes examined per individual.

c Fecal egg count, estimated per gram of wet feces (eggs/g). 
Table 2

Loading weights (LW) and percent contribution (\%) of predictor variables of the most parsimonious Partial Least Squares (PLS) regression model explaining the inflammatory response to PHA in Ctenomys talarum. Covariates in bold were statistically significant at $\alpha=0.05$. EV = Explained variance; the total variance of the inflammatory response to PHA explained by all $18 \mathrm{LVs}$. TV = Total variance of the inflammatory response to PHA.

\begin{tabular}{|c|c|c|c|c|}
\hline \multirow[b]{2}{*}{ Covariate } & \multicolumn{2}{|l|}{ LV 1} & \multicolumn{2}{|l|}{ LV 2} \\
\hline & LW & $\%$ & LW & $\%$ \\
\hline Sex & 0.171 & 2.933 & -0.097 & 0.950 \\
\hline Reproductive season & -0.227 & 5.158 & -0.537 & 28.855 \\
\hline Body weight & 0.303 & 9.156 & -0.124 & 1.535 \\
\hline Hematocrit & 0.154 & 2.358 & -0.142 & 2.008 \\
\hline Hemagglutination titre & 0.088 & 0.774 & 0.085 & 0.725 \\
\hline Fleas & 0.007 & 0.004 & 0.085 & 0.721 \\
\hline Hematophagous mites & 0.185 & 3.428 & 0.297 & 8.837 \\
\hline Non-hematophagous mites & 0.225 & 5.041 & 0.294 & 8.668 \\
\hline P. uncinata & 0.241 & 5.812 & 0.097 & 0.935 \\
\hline T. pampeana & -0.545 & 29.720 & -0.335 & 11.205 \\
\hline Eimeria sp. & -0.046 & 0.211 & 0.189 & 3.557 \\
\hline $\mathrm{N}: \mathrm{L}$ & 0.154 & 2.377 & -0.220 & 4.852 \\
\hline Neutrophils & 0.121 & 1.465 & -0.353 & 12.427 \\
\hline Lymphocytes & -0.140 & 1.950 & 0.196 & 3.826 \\
\hline Eosinophils & -0.379 & 14.389 & -0.591 & 34.956 \\
\hline Basophils & 0.103 & 1.053 & 0.246 & 6.042 \\
\hline Monocytes & -0.319 & 10.161 & -0.228 & 5.178 \\
\hline Total leukocytes & -0.200 & 4.009 & -0.228 & 5.178 \\
\hline$\% \mathrm{EV}$ & 62.8 & & 14.70 & \\
\hline$\%$ TV & 37.5 & & 8.79 & \\
\hline
\end{tabular}

\section{Results}

Thickness after $24 \mathrm{~h}$ of the PHA injection ranged from 0 to 1.03 $(0.46 \pm 0.03)$. Measures of individual condition obtained are shown in Table 1.

Maximum achievable explanation of the inflammatory response to PHA with all $18 \mathrm{LVs}$ was $60 \%$ of the total variance of the response. PLS regression provided two significant LVs comprising $77.5 \%$ of the total maximum achievable explained variance ( $62.8 \%$ and $14.7 \%$ by the first and second LVs, respectively).

The meaning of the components can be interpreted considering the weights attained by the covariates. The addition of the square of the weights within each component sums to one, so the contribution of each covariate to the meaning of each component can be easily estimated. The first component negatively associated the inflammatory response to PHA with the abundance of T. pampeana, and with counts of eosinophils and monocytes. The second component negatively associated the inflammatory response to PHA with reproductive activity, neutrophils and eosinophils (see Table 2 and Fig. 1).

The most important relationships of predictors in both LVs are depicted in Fig. 2. The relationship of the first LV with the inflammatory response showed that as the egg count of $T$. pampeana increases, inflammation decreases. The same pattern is observed regarding monocytes and eosinophils counts. The second LV captured the negative contributions of reproduction and the counts of eosinophils as well as neutrophils, over the PHA- induced inflammation.

\section{Discussion}

In the present study, 18 parameters related to different aspects of individual condition were obtained from wild-caught $C$. talarum individuals to analyze the basis of the important variation in the inflammatory response to PHA previously reported for the species (Merlo et al., 2014a). As predicted, some immunological attributes associated to infections appeared as modulators of the magnitude of inflammation induced by PHA. The predictors that best explained the variation of the PHA- induced inflammation involved, in addi-

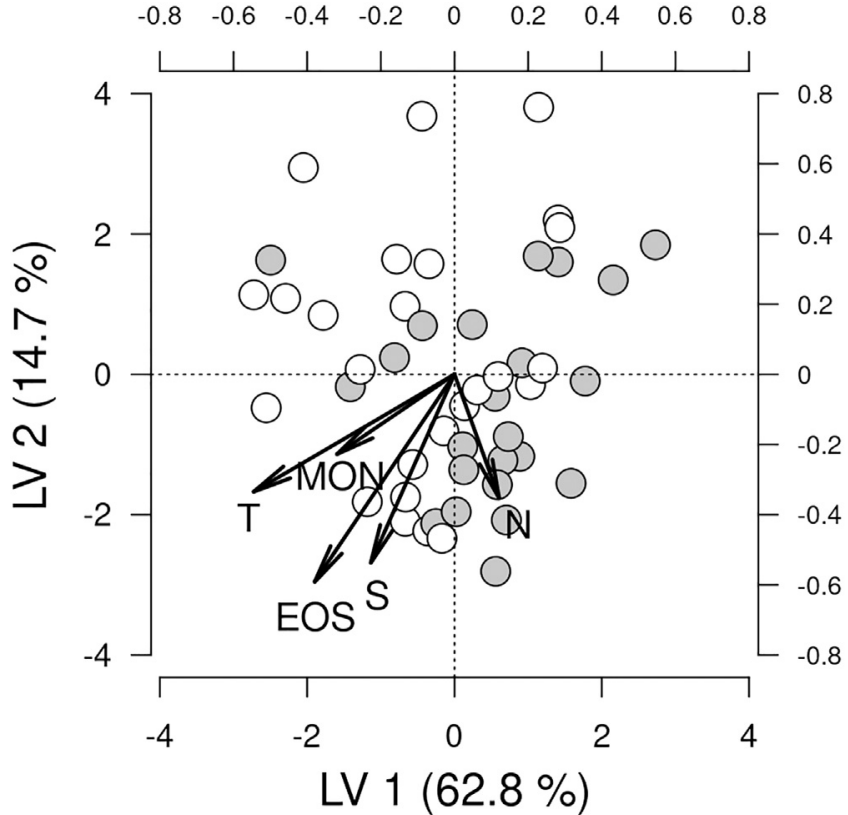

Fig. 1. Biplot of the first two latent vectors (LVs) obtained through Partial Least Squares (PLS) regression. Gray dots correspond to males and white dots to females. Only predictors that made statistically significant contributions to each LV are shown. EOS: eosinophils, MON: monocytes, N: neutrophils, S: reproductive season, T: T. pampeana.

tion to reproductive condition, the abundance of eggs of one of the six parasite taxa assessed (the nematode $T$. pampeana) and counts of eosinophils, monocytes and neutrophils, representing three of the seven hematological measures recorded. Of all the variables measured, reproductive condition and T. pampeana showed the most significant effect over the inflammation induced by PHA, showing a negative effect on this response. Contrary to our predictions, components of individual condition related to physical state (body weight, hematocrit) had no effect on the inflammatory response to PHA. Regarding to body weight, it is important to mention that this variable could not be corrected by body length given the aggressiveness of Talas tuco-tucos, which limits their manipulation; thus, body weight was also influenced by the sex of the animal, being males bigger than females in C. talarum. However, neither sex or body weight showed a significant relationship with the inflammatory response (in this study and previous work in the species; Merlo et al., 2014b). Finally, the agglutination capacity of plasma (a measure of innate immunity) did not show an association with the magnitude of PHA-induced inflammation either.

Intensity of infection by $T$. pampeana, estimated by fecal egg counts, was negatively related to the inflammatory response to PHA in Talas tuco-tucos. Host protective immunity against this parasite is typically Th2 (type 2 T lymphocyte mediated; Finkelman et al., 1997) and triggers the redistribution of eosinophils (Allen and Maizels, 2011; Hayward, 2013; Weil et al., 2006). In line with this, our data revealed that relative counts of eosinophils, as well as monocytes and neutrophils, in circulating blood of Talas tucotucos were also negatively related to the inflammatory response to PHA. In general, leukocyte counts from blood are informative of relatively recent infections. Therefore, our results provide additional support to the hypothesis that in Talas tuco-tucos parasitism is a key factor modulating the immune capacity to respond against new immune challenges, as was previously reported in individuals experimentally inoculated with infective oocysts of Eimeria sp. and with their natural parasite load (Merlo et al., 2016b). A negative effect of current $T$. pampeana infection on the immune response to a new challenge (i.e. PHA) could occur as a conse- 

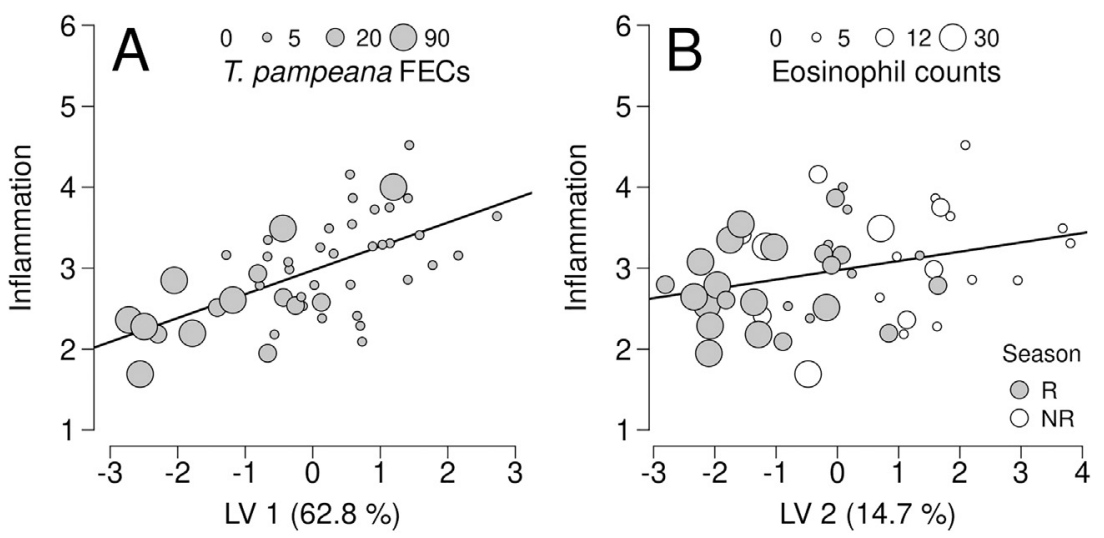

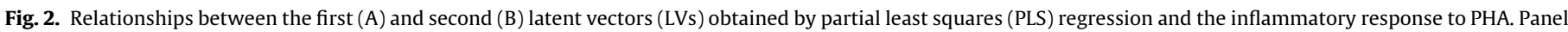

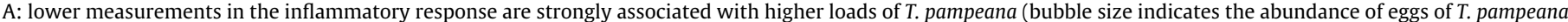

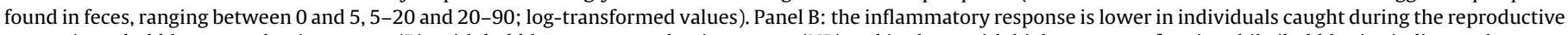

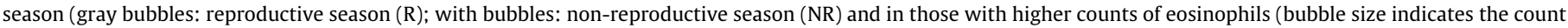
of eosinophils in blood, ranging between 0 and 5, 5-12 and 12-30; log-transformed values). FEC: fecal eggs count.

quence of reduction of the host's resources by the parasite (i.e. Khokhlova et al., 2002), thus limiting the development of energydemanding immune responses, or directly by interaction through immune components among both challenges (Weil et al., 2006). Based on our results, the first hypothesis seems unlikely; given that body weight did not influence the PHA response, detrimental effects of parasitism over the individual condition could have been compensated by the high availability of nutrients and energy provided by the ad libitum diet, and the reduction of costly activities (e.g., thermoregulation and digging) in captivity. Regarding the alternative hypothesis, mutual inhibition of Th1- (type $1 \mathrm{~T}$ lymphocyte mediated) and Th2- mediated responses is a welldescribed situation in co-infection (Cox, 2001). In our study, a typically Th2- mediated immune response against parasites, specifically $T$. pampeana, could have inhibited the adaptive component of the response to PHA (mediated by Th1 lymphocytes), resulting in a lower swelling response in more parasitized animals. Interestingly, the PHA- induced inflammation of white-toothed shrews, Crocidura russula, was found to be negatively related to cestode intensity and positively associated to nematode intensity, suggesting an antagonistic association between these groups of helminths, possibly mediated by immune components of the host (Goüy de Bellocq et al., 2007). Further, Behnke et al. (1983) showed that in Mus musculus, adult parasites Nematospiroides dubius are capable of modulating immunological activity at the intestinal level, thus preventing the host from eliminating worms during a chronic infection. Alternatively, the negative relationship between infection by T. pampeana and the PHA response observed in C. talarum could be a consequence of less immunocompetent individuals being more easily parasitized than individuals with stronger immune defenses. In C. talarum, Merlo et al. (2016b) reported that deparasitized animals mount a higher response to PHA than naturally parasitized animals or those experimentally-inoculated with infective oocysts of Eimeria sp., while the general condition is not influenced by the infectious condition. The absence of effect of Eimeria sp. on the PHA response in the present study in comparison with previous results could be a consequence of different study designs. Here, we used animals that differed in their natural levels of Eimeria sp. infection, while in Merlo et al. (2016b), significant effects were found when animals infected with high experimental loads of Eimeria sp. were compared with those treated with antiparasitic drugs (which shed almost no oocysts in their feces, and were all non-infective). This experimental design could have enhanced our capacity to detect these effects, while differences in Eimeria sp. loads were not as drastic in the wild.
According to the analysis performed here, reproductive condition also contributes to explain inflammation variability, suggesting that individuals may develop stronger inflammatory responses during the non-reproductive season. This may be a consequence of a trade-off in energy allocation between reproductive effort and immunity ("immunosuppressive hypothesis", see Deerenberg et al., 1997, Ardia, 2005, Greenman et al., 2005), a product of negative "pleiotropic" effects of reproductive hormones (e.g. testosterone) on immune function or both (Harshman and Zera, 2007). Additional studies are needed to elucidate this relationship in Talas tuco-tucos.

Interestingly, other parameters associated to individual condition, such as sex, body weight, hematocrit, and N: L, were not associated with the magnitude of inflammation in response to PHA. Given that this immune response is not energetically costly (Merlo et al., 2014b), the magnitude of this response could be independent of the general individual condition when environmental conditions are benign. The variability observed in the inflammatory response is more likely to be a consequence of different levels of infection among individuals (which is also supported by previous experiments conducted with Talas tuco-tucos in captivity; Merlo et al., 2016b), nutrition (Merlo et al., 2016a) and potentially other factors still unexplored (e.g. genetics).

Traits that are highly variable may be under more important phenotypic and environmental effects (Nussey, 2011). Here, using a multivariate approach, we were able to get a more complete assessment of the parameters that influence individual condition and its contribution to the remarkably high variation of the PHAinduced inflammatory response in C. talarum. Our results provide additional support for the influence of parasitism on one of the most frequently-used measures of immunocompetence available for studies of wild species in their natural habitat (Adelman, 2015). Specifically, we found that parasite load and reproductive condition may affect the PHA-induced inflammatory response.

Lee (2006) proposed that slow-living species are expected to rely more strongly on adaptive antibody-mediated immune responses, which are slower and generally more costly than innate responses, but confer immunological memory against repeated infections, that are more likely to occur in long-lived species. Our results showed that PHA-induced inflammation, which in Talas tuco-tucos is mediated by cells of the innate and adaptive branches (Merlo et al., 2014a), is negatively affected by certain parasite infections. On the contrary, Cutrera et al. (2011) reported that the antibody response triggered by the antigen sheep red blood cells (SRBC), despite being energetically expensive (Cutrera et al., 
2010), was not strongly associated with measures of parasite load or diversity. Overall our findings support the scenario proposed by Lee (2006), suggesting that in the "slow-living" tuco-tucos, the antibody responses are prioritized over other competing immune demands, which does not seem to be the case for the inflammatory response (Merlo et al., 2014b). An inverse pattern, where the inflammatory response is prioritized over adaptive immune responses, is expected in "fast-living" rodent species. Future studies on fast and slow-living rodents using this perspective may contribute to further our understanding of the role that immune defenses may play in mediating life history trade-offs.

\section{Acknowledgements}

This work was supported by Consejo Nacional de Investigaciones Científicas y Tecnológicas (CONICET) [PIP 0272] and Universidad Nacional de Mar del Plata, Argentina [EXA557/12].JLM was a fellow of Comisión de Investigaciones Científicas de la provincia de Buenos Aires during the first stage of this study, and later on, she was a fellow of CONICET. We thank two anonymous referees for helpful comments and suggestions that greatly improved the manuscript.

\section{References}

Abdi, H., 2010. Partial least squares regression and projection on latent structure regression (PLS Regression). Wiley Interdiscip. Rev. Comput. Stat. 2, 97-106.

Adelman, J.S., 2015. Immune systems: linking organisms, populations, and evolution through disease. In: Martin, L.B., Ghalambor, C.K., Woods, H.A. (Eds.), Integrative Organismal Biology. Wiley Blackwell, New Jersey, pp. 169-181.

Allen, J.E., Maizels, R.M., 2011. Diversity and dialogue in immunity to helminths. Nat. Rev. Immunol. 11, 375-388.

Ardia, D.R., 2005. Tree swallows trade off immune function and reproductive effort differently across their range. Ecology 86, 2040-2046.

Arjona Saz, Á., 2006. Células implicadas en la respuesta inmune. In: Gómez-Lucía, E., Blanco del, M.M., Doménech, A. (Eds.), Manual de Inmunología Veterinaria. Pearson Educación, Madrid, pp. 41-62.

Bachman, G.C., 2003. Food supplements modulate changes in leucocyte numbers in breeding male ground squirrels. J. Exp. Biol. 206, 2373-2380.

Barnard, C.J., Behnke, J.M., 2006. Behaviour, life history strategies and parasite infection in rodents. In: Morand, S., Krasnov, B.R., Poulin, R. (Eds.), Micromammals and Macroparasites: from Evolutionary Ecology to Management. Springer Japan, Tokyo, pp. 475-511.

Behnke, J.M., Hannah, J., Pritchard, D.I., 1983. Nematospiroides dubius in the mouse: evidence that adult worms depress the expression of homologous immunity. Parasite Immunol. 5, 397-408.

Beldomenico, P.M., Telfer, S., Gebert, S., Lukomski, L., Bennett, M., Begon, M., 2008a. Poor condition and infection: a vicious circle in natural populations. Proc. R. Soc. Lond. B Biol. Sci. 275, 1753-1759.

Beldomenico, P.M., Telfer, S., Gebert, S., Lukomski, L., Bennett, M., Begon, M., $2008 \mathrm{~b}$. The dynamics of health in wild field vole populations: a haematological perspective. J. Anim. Ecol. 77, 984-997.

Bertrand, F., Maumy-Bertrand, M., Meyer, N., 2014. Partial Least Squares Regression for Generalized Linear Models., pp. 150 (book of abstracts, Los Angeles. B. Abstr. 150).

Bishop, C.R., Athens, J.W., Boggs, D.R., Warner, H.R., Cartwright, G.E., Wintrobe, M.M., 1968. Leukokinetic studies. 13. A non-steady-state kinetic evaluation of the mechanism of cortisone-induced granulocytosis. J. Clin. Invest. 47, 249-260.

Boonstra, R., McColl, C., Karels, T., 2001. Reproduction at all costs: the adaptive stress response of male arctic ground squirrels. Ecology 82, 1930-1946.

Boughton, R.K., Joop, G., Armitage, S.A.O., 2011. Outdoor immunology: methodological considerations for ecologists. Funct. Ecol. 25, 81-100.

Brown, C.R., Brown, M.B., 1989. Ectoparasitism as a cost of coloniality in cliff swallows (Hirundo Pyrrhonota). Ecology 67, 1206-1218.

Brown, G.P., Shilton, C.M., Shine, R., 2011. Measuring amphibian immunocompetence: validation of the phytohemagglutinin skin-swelling assay in the cane toad, Rhinella marina. Methods Ecol. Evol. 2, 341-348.

Busch, C., Malizia, A.I., Scaglia, O.A., Reig, O.A., 1989. Spatial distribution and attributes of a population of Ctenomys talarum (Rodentia: octodontidae). J. Mammal. 70, 204-208.

Busch, C., Antinuchi, C.D., del Valle, J.C., Kittlein, M., Malizia, A.I., Vassallo, A.I., Zenuto, R.R., 2000. Population ecology of subterranean rodents. In: Lacey, E.A., Cameron, G., Patton, J.L. (Eds.), Life Underground: The Biology of Subterranean Rodents. University of Chicago Press, Chicago, Illinois, pp. 183-226.

Carrascal, L.M., Galván, I., Gordo, O., 2009. Partial least squares regression as an alternative to current regression methods used in ecology. Oikos 118, 681-690.
Christe, P., Glaizot, O., Strepparava, N., Devevey, G., Fumagalli, L., 2011. Twofold cost of reproduction: an increase in parental effort leads to higher malarial parasitaemia and to a decrease in resistance to oxidative stress. Proc. Biol. Sci. 279, 1142-1149.

Cohen, A.A., Martin, L.B., Wingfield, J.C., McWilliams, S.R., Dunne, J.A., 2012. Physiological regulatory networks: ecological roles and evolutionary constraints. Trends Ecol. Evol. 27, 428-435.

Cox, F.E.G., 2001. Concomitant infections, parasites and immune responses. Parasitology 122, 23-38.

Cuello-Gijón, F., 2006. Introducción. In: Gómez-Lucía, E., Blanco, M., del, M. Doménech, A. (Eds.), Manual de Inmunología Veterinaria. Pearson Educación, Madrid, pp. 1-20.

Cutrera, A.P., Zenuto, R.R., Luna, F., Antenucci, C.D., 2010. Mounting a specific immune response increases energy expenditure of the subterranean rodent Ctenomys talarum (tuco-tuco): implications for intraspecific and interspecific variation in immunological traits. J. Exp. Biol. 213, 715-724.

Cutrera, A.P., Zenuto, R.R., Lacey, E.A., 2011. MHC variation, multiple simultaneous infections and physiological condition in the subterranean rodent Ctenomys talarum. Infect. Genet. Evol. 11, 1023-1036.

Davis, A.K., Maney, D.L., Maerz, J.C., 2008. The use of leukocyte profiles to measure stress in vertebrates: a review for ecologists. Funct. Ecol. 22, 760-772.

Deerenberg, C., Arpanius, V., Daan, S., Bos, N., 1997. Reproductive effort decreases antibody responsiveness. Proc. R. Soc. B Biol. Sci. 264, 1021-1029.

Dhabhar, F.S., 2009. Enhancing versus suppressive effects of stress on immune function: implications for immunoprotection and immunopathology. Neuroimmunomodulation 16, 300-317.

Fargallo, J.A., Laaksonen, T., Poyri, V., Korpimaki, E., 2002. Inter-sexual differences in the immune response of Eurasian kestrel nestlings under food shortage. Ecol. Lett. 5, 95-101

Finkelman, F.D., Shea-Donohue, T., Goldhill, J., Sullivan, C.a., Morris, S.C., Madden, K.B., Gause, W.C., Urban, J.F., 1997. Cytokine regulation of host defense against parasitic gastrointestinal nematodes: lessons from studies with rodent models. Annu. Rev. Immunol. 15, 505-533.

Goüy de Bellocq, J., Ribas, A., Casanova, J.C., Morand, S., 2007. Immunocompetence and helminth community of the white-toothed shrew, Crocidura russula from the Montseny Natural Park, Spain. Eur. J. Wildl. Res. 53, 315-320.

Greenman, C.G., Martin, L.B., Hau, M., 2005. Reproductive state, but not testosterone, reduces immune function in male house sparrows (Passer domesticus). Physiol. Biochem. Zool. 78, 60-68.

Harshman, L.G., Zera, A.J., 2007. The cost of reproduction: the devil in the details. Trends Ecol. Evol. 22, 80-86

Hayward, a.D., 2013. Causes and consequences of intra- and inter-host heterogeneity in defence against nematodes. Parasite Immunol. 35, 362-373.

Hoi-Leitner, M., Romero-Pujante, M., Hoi, H., Pavlova, A., 2001. Food availability and immune capacity in serin (Serinus serinus) nestlings. Behav. Ecol. Sociobiol. 49, 333-339.

Huyghe, K., Van Oystaeyen, A., Pasmans, F., Tadić, Z., Vanhooydonck, B., van Damme, R., 2010. Seasonal changes in parasite load and a cellular immune response in a colour polymorphic lizard. Oecologia 163, 867-874.

Jakob, E.M., Marshall, S.D., Uetz, G.W., 1996. Estimating fitness: a comparison of body condition indices. Oikos 77, 61-67.

Jones, A., Bailey, T.A., Nothelfer, H.B., Gibbons, L.M., Samour, J.H., Bowardi, M.A. Osborne, P., 1996. Parasites of wild houbara bustards in the United Arab Emirates. J. Helminthol. 70, 21-25.

Khokhlova, I.S., Krasnov, B.R., Kam, M., Burdelova, N.I., Degen, A.A., 2002. Energy cost of ectoparasitism: the flea Xenopsylla ramesis on the desert gerbil Gerbillus dasyurus. J. Zool. 258, 349-354.

Khokhlova, I.S., Spinu, M., Krasnov, B.R., Degen, A.A., 2004. Immune responses to fleas in two rodent species differing in natural prevalence of infestation and diversity of flea assemblages. Parasitol. Res. 94, 304-311.

Knowles, S.C.L., Nakagawa, S., Sheldon, B.C., 2009. Elevated reproductive effort increases blood parasitaemia and decreases immune function in birds: a meta-regression approach. Funct. Ecol. 23, 405-415.

Lazzaro, B.P., Little, T.J., 2009. Immunity in a variable world. Philos. Trans. R. Soc. B Biol. Sci. 364.

Lee, K.A., 2006. Linking immune defenses and life history at the levels of the individual and the speces. Integr. Comp. Biol. 46, 1000-1015.

Luna, F., Antinuchi, C.D., 2007. Energy and distribution in subterranean rodents: sympatry between two species of the genus Ctenomys. Comp. Biochem. Physiol. - A Mol. Integr. Physiol. 147, 948-954.

Møller, A.P., Erritzøe, J., Saino, N., 2003. Seasonal changes in immune response and parasite impact on hosts. Am. Nat. 161, 657-671.

Müller, C., Jenni-Eiermann, S., Jenni, L., 2011. Heterophils/Lymphocytes-ratio and circulating corticosterone do not indicate the same stress imposed on Eurasian kestrel nestlings. Funct. Ecol. 25, 566-576.

Malizia, A.I., Busch, C., 1991. Reproductive parameters and growth in the fossorial rodent Ctenomys talarum (Rodentia: Octodontidae). Mammalia 55, 293-306.

Martin, L.B., Pless, M., Svoboda, J., Wikelski, M., 2004. Immune activity in temperate and tropical House Sparrows: a common-garden experiment. Ecology 85, 2323-2331.

Martin, L.B., 2009. Stress and immunity in wild vertebrates: timing is everything. Gen. Comp. Endocrinol. 163, 70-76.

Martino, N.S., Romero, M.D., Malizia, A.I., 2014. Parasitism underground: lice (Insecta: Phthiraptera) from Ctenomys talarum (Rodentia: Ctenomyidae) along its coastal distribution in Argentina. Acta Parasitol. 60, 154-157. 
Matson, K.D., Ricklefs, R.E., Klasing, K.C., 2005. A hemolysis-hemagglutination assay for characterizing constitutive innate humoral immunity in wild and domestic birds. Dev. Comp. Immunol. 29, 275-286.

Matson, K.D., Cohen, A.a., Klasing, K.C., Ricklefs, R.E., Scheuerlein, A., 2006. No simple answers for ecological immunology: relationships among immune indices at the individual level break down at the species level in waterfowl. Proc. Biol. Sci. 273, 815-822.

McEwen, B.S., Wingfield, J.C., 2010. What is in a name? Integrating homeostasis, allostasis and stress. Horm. Behav. 57, 105-111.

Merlo, J.L., Cutrera, A.P., Luna, F., Zenuto, R.R., 2014a. PHA-induced inflammation is not energetically costly in the subterranean rodent Ctenomys talarum (tuco-tucos). Comp. Biochem. Physiol. A Mol. Integr. Physiol. 175, 90-95.

Merlo, J.L., Cutrera, A.P., Zenuto, R.R., 2014b. Inflammation in response to phytohemagglutinin injection in the Talas tuco-tuco (Ctenomys talarum): implications for the estimation of immunocompetence in natural populations of wild rodents. Can. J. Zool. 92, 689-697.

Merlo, J.L., Cutrera, A.P., Zenuto, R.R., 2016a. Food restriction affects inflammatory response and nutritional state in Tuco-tucos (Ctenomys talarum). J. Exp. Zool. Part A Ecol. Genet. Physiol. 325, 675-687.

Merlo, J.L., Cutrera, A.P., Zenuto, R.R., 2016b. Parasite infection negatively affects PHA- triggered inflammation in the subterranean rodent. J. Exp. Zool. 325 , $132-141$.

Nunn, C.L., Lindenfors, P., Pursall, E.R., Rolff, J., 2009. On sexual dimorphism in immune function. Philos. Trans. R. Soc. Lond. B Biol. Sci. 364, 61-69.

Nussey, D.H., 2011. The ecological and evolutionary importance of variation in life history reaction norms. In: Martin, L.B., Ghalambor, C.K., Woods, H.A. (Eds.), Integrative Organismal Biology. Wiley Blackwell, New Jersey, pp. 23-38.

Oliver-Guimerá, A., Martínez-Carrasco, C., Tvarijonaviciute, A., Ruiz de Ybáñez, M.R., Martínez-Guijosa, J., López-Olvera, J.R., Fernández-Aguilar, X. Colom-Cadena, A., Mentaberre, G., Velarde, R., Gassó, D., Garel, M., Rossi, L., Lavín, S., Serrano, E., 2017. The physiological cost of male-biased parasitism in a nearly monomorphic mammal. Parasite Vectors 10, 200.

Pedersen, A.B., Babayan, S.A., 2011. Wild immunology. Mol. Ecol. 20, 872-880.

Peig, J., Green, A.J., 2009. New perspectives for estimating body condition from mass/length data: the scaled mass index as an alternative method. Oikos 118, 1883-1891.

Powell, N.D., Sloan, E.K., Bailey, M.T., Arevalo, J.M.G., Miller, G.E., Chen, E., Kobor, M.S., Reader, B.F., Sheridan, J.F., Cole, S.W., 2013. Social stress up-regulates inflammatory gene expression in the leukocyte transcriptome via-adrenergic induction of myelopoiesis. Proc. Natl. Acad. Sci. 110, 16574-16579.

Restif, O., Amos, W., 2010. The evolution of sex-specific immune defences. Proc. Biol. Sci. 277, 2247-2255.

Richner, H., Oppliger, A., Christe, P., 1993. Effect of an ectoparasite on reproduction in great tits. J. Anim. Ecol. 62, 703-710.

Rossin, M.A., Malizia, A.I., 2002. Relationship between helminth parasites and demographic attributes of a population of the subterranean rodent Ctenomys talarum (Rodentla: Octodontidae). J. Parasitol. 88, 1268-1270.

Rossin, A., Malizia, A.I., Denegri, G.M., 2004. The role of the subterranean rodent Ctenomys talarum (Rodentia: Octodontidae) in the life cycle of Taenia taeniaeformis (Cestoda: Taeniidae) in urban environments. Vet. Parasitol. 122 27-33.

Rossin, M.A., Poulin, R., Timi, J.T., Malizia, a. I., 2005. Causes of inter-individual variation in reproductive strategies of the parasitic nematode Graphidioides subterraneus. Parasitol. Res. 96, 335-339.

Rossin, M.A., Timi, J.T., Malizia, A.I., 2006. New pudicinae (Trichostrongylina, Heligmosomoidea), Pudica ctenomydis n. sp. parasite of Ctenomys talarum (Rodentia: Octodontidae) from Argentina. Parasitol. Int. 55, 83-87.
Rossin, M.A., Malizia, A.I., Timi, J.T., Poulin, R., 2010. Parasitism underground: determinants of helminth infections in two species of subterranean rodents (Octodontidae). Parasitology 137, 1569-1575.

Russolillo, G., Lauro, C.N., 2009. A proposal for handling categorical predictors in pls regression framework. In: Fichet, B., Piccolo, D., Verde, R., Vichi, M. (Eds.), Classification and Multivariate Analysis for Complex Data Structures. Springer Heidelberg Dordrecht, New York, pp. 343-350.

Salinas Lorente, J., 2006. Inmunidad frente a agentes eucariotas patógenos. In: Gómez-Lucía, E., Blanco, M., del, M., Doménech, A. (Eds.), Manual de inmunología veterinaria. Pearson Educación, Madrid, pp. 450-469.

Sanchez, G., Trinchera, L., Russolillo, G., 2017. Plspm: Tools for Partial Least Squares Path Modeling (PLS-PM). R package version 04.9 http://CRAN.Rproject.org/ package= plspm.

Sapolsky, R.M., Romero, L.M., Munck, A.U., 2000. How do glucocorticoids influence stress responses? Integrating permissive, suppressive, stimulatory, and preparative actions. Endocr. Rev. 21, 55-89.

Schmid-Hempel, P., 2003. Variation in immune defence as a question of evolutionary ecology. Proc. Biol. Sci. 270, 357-366.

Serbina, N.V., Jia, T., Hohl, T.M., Pamer, E.G., 2008. Monocyte-mediated defense against microbial pathogens. Annu. Rev. Immunol. 26, 421-452.

Sheather, A.L., 1923. The detection of intestinal protozoa and mange parasites by a floatation technique. J. Comp. Pathol. Ther. 36, 266-275.

Sheldon, B.C., Verhulst, S., 1996. Ecological immunology: costly parasite defences and trade-offs in evolutionary ecology. Trends Ecol. Evol. 11, 317-321.

Team, R.C., 2016. R: A Language and Environment for Statistical Computing. R Foundation for Statistical Computing, Vienna, Austria, pp. 2015 (URL http. www.R-project.org).

van der Most, P.J., de Jong, B., Parmentier, H.K., Verhulst, S., 2011. Trade-off between growth and immune function: a meta-analysis of selection experiments. Funct. Ecol. 25, 74-80.

Vera, F., Zenuto, R.R., Antenucci, C.D., 2008. Decreased glucose tolerance but normal blood glucose levels in the field in the caviomorph rodent Ctenomys talarum: The role of stress and physical activity. Comp. Biochem. Physiol. - A Mol. Integr. Physiol. 151, 232-238.

Voigt, G.L., 2000. Hematology Techniques and Concepts for Veterinary Technicians. John Wiley \& Sons, IA, USA.

Wakelin, P., 2009. Genetic control of immune responses to parasites: immunity to Trichuris muris in inbred and random-bred strains of mice. Parasitology 71, 51

Weil, Z.M., Martin, L.B., Nelson, R.J., 2006. Interactions among immune, endocrine, and behavioural response to infection. In: Micromammals and Macroparasites. Springer, Japan, Tokyo, pp. 443-473.

Xu, D.-L., Wang, D.-H., 2010. Fasting suppresses T cell-mediated immunity in female Mongolian gerbils (Meriones unguiculatus). Comp. Biochem. Physiol. A Mol. Integr. Physiol. 155, 25-33.

Zahorec, R., 2001. Ratio of neutrophil to lymphocyte counts-rapid and simple parameter of systemic inflammation and stress in critically ill. Bratisl. Lek. Listy 102, 5-14.

Zenuto, R.R., Antinuchi, C.D., Busch, C., 2002a. Bioenergetics of reproduction and pup development in a subterranean rodent (Ctenomys talarum). Physiol. Biochem. Zool. Ecol. Evol. Approaches 75, 469-478.

Zenuto, R.R., Vassallo, A.I., Busch, C., 2002b. Social and reproductive behavior of the subterranean solitary rodent Ctenomys talarum (Rodentia: Ctenomyidae) in a seminatural enclosure. Rev. Chil. Hist. Nat. 75, 165-177. 